\title{
Cardiorespiratory responses in an Antarctic fish suggest limited capacity for thermal acclimation
}

\author{
Stuart Egginton ${ }^{1, *}$ and Hamish A. Campbell ${ }^{2}$
}

\begin{abstract}
Polar fishes are at high risk from increasing seawater temperatures. Characterising the physiological responses to such changes may both clarify mechanisms that permit life under extreme conditions and identify limitations in the response to continued global warming. We hypothesised that Notothenia coriiceps would show physiological compensation after an acute exposure to $5^{\circ} \mathrm{C}$, and following 6 weeks warm acclimation, compared with ambient temperature $\left(0^{\circ} \mathrm{C}\right)$. However, initial tachycardia (22.4 \pm 2.8 versus $\left.12.8 \pm 1.1 \mathrm{~min}^{-1} ; P<0.01\right)$ was not reversed by acclimation $\left(21.0 \pm 1.9 \mathrm{~min}^{-1}\right)$. Hyperventilation $(45.5 \pm 3.1$ versus $21.4 \pm 2.4$ breaths $\left.\mathrm{min}^{-1} ; \quad P<0.001\right)$ showed a modest reduction following acclimation $\left(38.0 \pm 2.9 \mathrm{~min}^{-1} ; \quad P<0.05\right)$, while resting oxygen consumption $\left(0.52 \pm 0.08 \mathrm{mmol} \mathrm{kg}^{-1} \mathrm{~h}^{-1}\right)$ was acutely increased at $5^{\circ} \mathrm{C} \quad\left(1.07 \pm 0.10 \mathrm{mmol} \mathrm{kg}^{-1} \mathrm{~h}^{-1} ; \quad P<0.001\right)$ but unchanged with acclimation. Autonomic blockade showed initial responses were mainly of vagal origin, with little subsequent withdrawal or recovery in long-term heart rate variability after 6 weeks. Given the limited cardiorespiratory capacity to withstand sustained warming, effective physiological compensation probably requires a more prolonged acclimation period.
\end{abstract}

KEY WORDS: Heart rate variability, Oxygen consumption, Vagal tone

\section{INTRODUCTION}

One region where measuring thermal sensitivity in ectotherms is of imminent importance is the stenothermal aquatic environment of the Southern Ocean. Here, fishes experience one of the narrowest annual excursions in environmental temperature, but along the Antarctic Peninsula inhabit a region undergoing one of the most rapid rates of seawater warming on the planet. This may have significant consequences for species distribution, given that the upper incipient lethal temperature (UILT) of the dominant notothenioid fishes is thought to be quite modest, between 5 and $7^{\circ} \mathrm{C}$ (O'Brien and Crockett, 2013; Somero and DeVries, 1967). It is therefore of interest to explore the extent and underlying mechanisms of the thermal plasticity in these fishes, which remain unclear (Somero and DeVries, 1967). Notothenioids are considered by many to be highly specialised for life in stable cold waters, and regarded as the archetypal stenotherms. However, some nototheniids show evidence for a greater thermal tolerance than initially reported in terms of cardiac performance, locomotor capacity, osmoregulation, metabolic compensation and loss of equilibrium (Egginton et al., 2006; Seebacher et al., 2005). In some

\footnotetext{
${ }^{1}$ Multidisciplinary Cardiovascular Research Centre, School of Biomedical

Sciences, University of Leeds, Garstang 5.64, Clarendon Way, Leeds LS2 9JT, UK.

${ }^{2}$ School of the Environment, Charles Darwin University, Darwin, NT 0909, Australia.

*Author for correspondence (s.egginton@leeds.ac.uk)
}

Received 1 September 2015; Accepted 16 February 2016 cases, this may be accompanied by significant mortality on acclimation, but there may be sufficient phenotypic plasticity in these closely related, endemic species to confer a species-level advantage in accommodating a rapidly changing thermal environment. Although many animals are able to adjust their heat tolerance in response to their thermal history, the capacity of Antarctic fishes for acclimation to elevated temperatures appears to be rather limited, e.g. warm acclimation increased the upper critical temperature $\left(\mathrm{CT}_{\max }\right)$ by $<18^{\circ} \mathrm{C}$, much less than observed with temperate zone species (Bilyk and DeVries, 2011).

Current data suggest that cardiac performance may be a key factor in limiting the thermal tolerance of fishes (Farrell et al., 2009). Indeed, maximum heart rate during warming of Pagothenia borchgrevinki occurred at $6^{\circ} \mathrm{C}$, the UILT of Antarctic fishes (Robinson et al., 2011). Antarctic notothenioids regulate cardiac output largely by heart rate $\left(f_{\mathrm{H}}\right)$ rather than stroke volume $(\mathrm{SV})$, and display a low $f_{\mathrm{H}}$ as a result of a high cholinergic tonus on the cardiac pacemaker. They also possess a relatively large heart, a low number of circulating erythrocytes and a high plasma lipid content compared with temperate zone teleosts (Egginton et al., 2006). These cardiovascular adaptations probably evolved in response to low environmental (and hence core) temperature, leading to high solubility of oxygen in seawater and body fluids, low diffusion rates of oxygen into tissue, increased blood viscosity and reduced rates of biochemical reactions compared with other teleosts (Beers and Jayasundara, 2015; Egginton et al., 2006). However, thermal compensation of $P$. borchgrevinki preserved cardiac support for aerobic exercise by changing both $f_{\mathrm{H}}$ and $\mathrm{SV}$ in the cold, but only $f_{\mathrm{H}}$ at high temperatures (Franklin et al., 2007).

Notothenia coriiceps, a member of the dominant sub-order of nototheniids, shows pronounced seasonal variation in both heart rate and oxygen consumption that is largely under vagal control, despite only minor changes in environmental temperature (Campbell et al., 2008). We hypothesised that $N$. coriiceps would demonstrate a modulation of autonomic control over chronic (6 weeks) compared with acute (1 day) thermal challenges, and this would be reflected in the cardiorespiratory response. The influence on $f_{\mathrm{H}}$, and cardiorespiratory integration, may then reflect their ability to accommodate changes in the thermal environment. Indeed, cardiorespiratory responses to temperature change may be a more sensitive index of thermal tolerance than traditional measures such as the $\mathrm{CT}_{\max }$ test. Given adaptation over $\sim 22$ million years to a consistently cold habitat, we reasoned that Antarctic fish will probably display only partial compensation to (relatively shortterm) increases in water temperature. If the mechanisms supporting thermal plasticity are limited, effective thermal adaptation over generations in these animals may be possible only if the extent of the temperature rise is modest and/or the rate of change is sufficiently slow to maintain a viable population in response to selection pressure, while avoiding impacts on long-term growth and reproduction. 


\section{MATERIALS AND METHODS}

Notothenia coriiceps J. Richardson 1844 (350-500 g, N=8) were caught by set-net around Rothera Research Station (British Antarctic Survey), Adelaide Island $\left(67^{\circ} 34^{\prime} \mathrm{S}, 68^{\circ} 08^{\prime} \mathrm{W}\right)$, Antarctica. Fish were allowed to recover from capture stress for a minimum of 2 weeks in aerated seawater at ambient temperature $\left(\sim 0^{\circ} \mathrm{C}\right)$ and constant photoperiod $(24 \mathrm{~h}$ light) before use. All experiments were conducted in accordance with the UK Animals (Scientific Procedures) Act 1986, with surgical procedures undertaken in an air-cooled room $\left(0^{\circ} \mathrm{C}\right)$. Fish were anaesthetised (MS222, $0.3 \mathrm{~g} \mathrm{l}^{-1}$ ) then placed on an operating table and the gills irrigated with aerated seawater (MS222, $\left.0.1 \mathrm{~g} \mathrm{l}^{-1}\right)$. Multi-strand Teflon-coated stainless steel wire (A-M Systems, USA), used for electrocardiogram (ECG) recording electrodes to measure $f_{\mathrm{H}}$, and an intraperitoneal catheter, used for drug delivery, were implanted as previously described (Campbell and Egginton, 2007; Campbell et al., 2006). The fish were allowed to recover in fresh aerated water then placed into a metabolic recording chamber, with the ECG leads exiting through the top of the chamber, and were not disturbed or fed for $96 \mathrm{~h}$ before initial readings were taken.

The amplified ECG signal from unanaesthetised animals was recorded at $400 \mathrm{~Hz}$ in real time (PowerLab; AD Instruments, Oxford, UK), and inter-beat intervals ( $\mathrm{R}-\mathrm{R}$; the period between $\mathrm{R}$ waves of successive heart beats) were extracted from the raw trace. Ventilation rate $\left(f_{\mathrm{V}}\right)$ was assessed from opercular movement, determined by a low-frequency component of the ECG trace resulting from a shift in the isoelectric baseline. Levels of cholinergic $(\% \mathrm{Ch})$ and adrenergic tonus $(\% \mathrm{Ad})$ on the heart were calculated as follows:

$$
\begin{aligned}
& \% \mathrm{Ch}=100\left[(\mathrm{R}-\mathrm{R})_{\text {cont }}-(\mathrm{R}-\mathrm{R})_{\text {musc }}\right] /(\mathrm{R}-\mathrm{R})_{0}, \\
& \% \mathrm{Ad}=100\left[(\mathrm{R}-\mathrm{R})_{0}-(\mathrm{R}-\mathrm{R})_{\text {musc }}\right] /(\mathrm{R}-\mathrm{R})_{0},
\end{aligned}
$$

where $(\mathrm{R}-\mathrm{R})_{\text {cont }}$ is the control $\mathrm{R}-\mathrm{R}$ interval, $(\mathrm{R}-\mathrm{R})_{\text {musc }}$ is the $\mathrm{R}-\mathrm{R}$ interval after muscarinic receptor blockade $\left(1 \mathrm{mg} \mathrm{kg}^{-1}\right.$ atropine) and $(\mathrm{R}-\mathrm{R})_{0}$ is the $\mathrm{R}-\mathrm{R}$ interval after complete autonomic blockade ( $1 \mathrm{mg} \mathrm{kg}^{-1}$ atropine $+1 \mathrm{mg} \mathrm{kg}^{-1}$ propranolol).

Geometrical analysis of ECG parameters was conducted on records free from ectopic beats or signal artefacts. $f_{\mathrm{H}}$ variability was assessed for the degree of long-term or short-term variation, as visualised in Poincare plots, using standard deviation of the $\mathrm{R}-\mathrm{R}$ interval (SDRR) and standard deviation of the successive differences of $\mathrm{R}-\mathrm{R}$ intervals (SDSD), respectively. To determine the relative importance of these components, $f_{\mathrm{H}}$ variability was expressed as the ratio SDRR:SDSD. Frequency domain analysis used a dataset of 256 consecutive $\mathrm{R}-\mathrm{R}$ intervals, with a fast Fourier transformation applied using a Hanning window to minimise spectral leakage (Campbell and Egginton, 2007; Campbell et al., 2006).

Whole-animal oxygen consumption rate $\left(\dot{M}_{\mathrm{O}_{2}}\right)$ was measured to determine aerobic metabolic rate in fish whilst undertaking $f_{\mathrm{H}}$ and $f_{\mathrm{V}}$ measurements, as described previously (Campbell et al., 2008). Once the fish was placed inside the metabolic recording chamber, $\dot{M}_{\mathrm{O}_{2}}$ measurements commenced and ran continuously for $144 \mathrm{~h}$; oxygen tension was sampled every $15 \mathrm{~min}$. In a second group of fish, after the recovery period, the holding tank temperature was raised to $5^{\circ} \mathrm{C}$, at a rate of $0.2^{\circ} \mathrm{C} \mathrm{h}^{-1}$ to minimise the stress response, i.e. to just below the reported UILT (Somero and DeVries, 1967), and readings taken at this point. A third group of fish were analysed at $5^{\circ} \mathrm{C}$ using a similar protocol, following 6 weeks acclimation.

Significant differences between conditions were assessed using multi-factorial ANOVA, with post hoc tests using Fisher's protected least-significant difference (PLSD) procedure to discriminate amongst group means $(P<0.05)$. Animals were chosen at random, and required experimental sample size was estimated using Power analysis.

\section{RESULTS AND DISCUSSION}

Cardiovascular control and/or cardiorespiratory regulation may be key to the markedly low thermal tolerance of notothenioids, and their ability to sustain useful activity in the face of imminent environmental challenges (Egginton et al., 2006). The low resting $f_{\mathrm{H}}, f_{\mathrm{V}}$ and $\dot{M}_{\mathrm{O}_{2}}$ were appropriate for the environmental conditions, and consistent with previous findings (Campbell et al., 2008). These indices of cardiorespiratory function showed a marked elevation on acute exposure to a $5^{\circ} \mathrm{C}$ rise in water temperature $\left(Q_{10}=3.06,4.52\right.$ and 4.23, respectively; Fig. 1). This was accompanied by $\sim 20 \%$ greater cardiorespiratory coupling $\left(\mathrm{CRC}=f_{\mathrm{V}} / f_{\mathrm{H}} ; 1.67\right.$ versus 2.03$)$ and oxygen pulse $\left(\dot{M}_{\mathrm{O}_{2}} / f_{\mathrm{H}} ; 0.041\right.$ versus $0.048 \mathrm{mmol} \mathrm{kg}^{-1} \mathrm{~h}^{-1}$ per beat), implying a slower but deeper ventilatory rhythm supporting the higher metabolic demand at elevated temperatures. The merits of
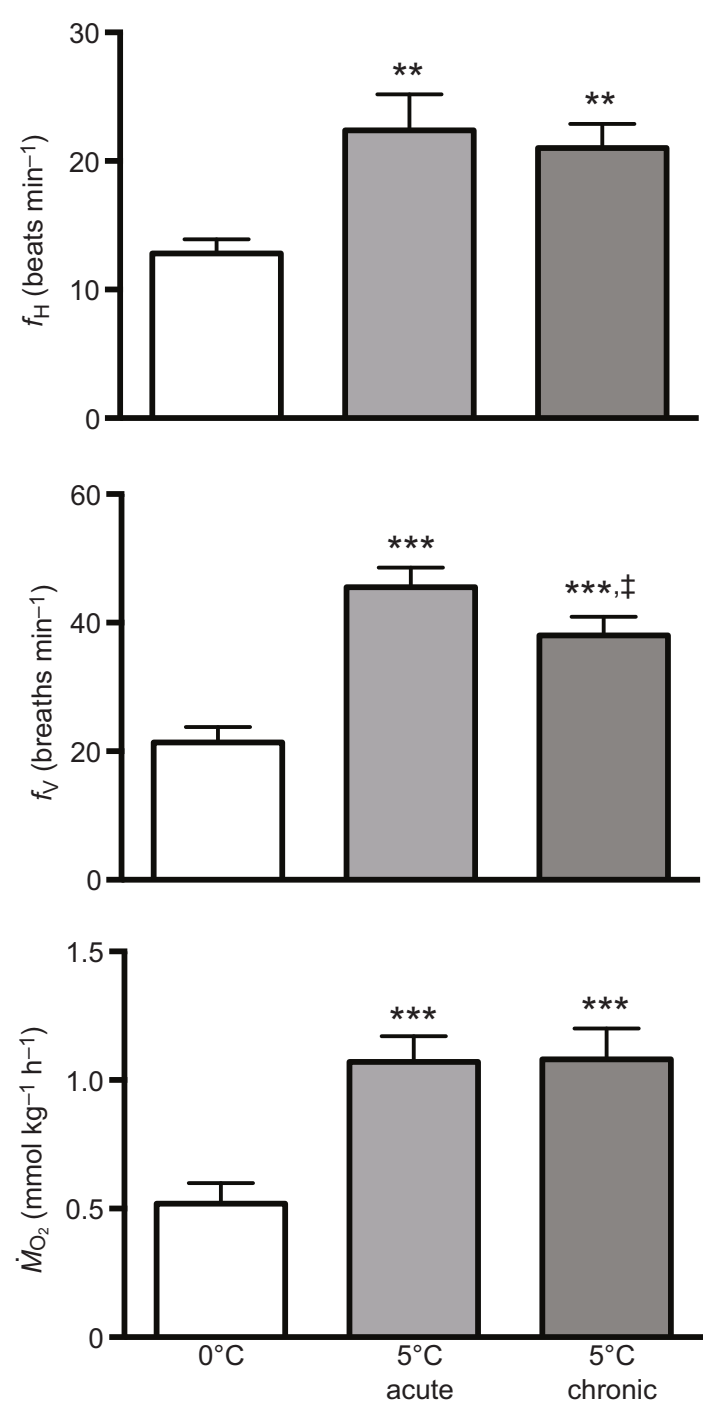

Fig. 1. Influence of acute and chronic exposure to $5^{\circ} \mathrm{C}$ on heart rate $\left(f_{\mathrm{H}}\right)$, ventilation rate $\left(f_{\mathrm{v}}\right)$ and oxygen consumption $\left(\dot{M}_{\mathrm{O}_{2}}\right)$ in Notothenia coriiceps. Fish were exposed to a temperature rise over 1 day or for a 6 week period. Data are means+s.e.m., $N=8$ animals in each group. ${ }^{* *} P<0.01$, ${ }^{* * *} P<0.001$ versus $0^{\circ} \mathrm{C} ;{ }^{\ddagger} P<0.05$ versus $5^{\circ} \mathrm{C}$ acute (factorial ANOVA). 
CRC are unclear, e.g. whether an integer value of $f_{\mathrm{V}} / f_{\mathrm{H}}$ confers greater efficacy of $\mathrm{O}_{2}$ transfer across the gills by effecting a synchrony between branchial perfusion and opercular flow. In a temperate notothenioid, it was clear that CRC was not essential for optimising gas exchange, and an increase in ventilation volume rather than frequency is likely to be more energetically efficient because of the inertial forces required to ventilate in a relatively dense medium (Campbell and Egginton, 2007). Stress-induced increases in $\dot{M}_{\mathrm{O}_{2}}$ lead to proportionately greater increases in $f_{\mathrm{H}}$ than $f_{\mathrm{V}}$, so the opposite response here is perhaps surprising and implicates a direct thermal influence on central rhythm generation that matches an increase in $\dot{M}_{\mathrm{O}_{2}}$.

We therefore tested how adaptable autonomic control is to temperature change. As expected, $f_{\mathrm{H}}$ variability was greatly reduced at the higher temperature, and Poincare plots demonstrated this for both long-term $\left(\mathrm{SDRR}=386 \pm 76\right.$ versus $124 \pm 46 \mathrm{~ms}$ for $0^{\circ} \mathrm{C}$ versus acute $5^{\circ} \mathrm{C}$ animals; $\left.P<0.01\right)$ and short-term $(\mathrm{SDSD}=523 \pm 89$ versus $103 \pm 56 \mathrm{~ms}$, respectively; $P<0.001)$ indices. This reflects the effects of both a reduced vagal tone $\left(52 \%\right.$ at $0^{\circ} \mathrm{C}$ versus $31 \%$ at $\left.5^{\circ} \mathrm{C}\right)$ and a rise in adrenergic tone ( $13 \%$ versus $20 \%$, respectively) on $f_{\mathrm{H}}$. Consistent with induced stress or seasonal changes in temperature (Campbell et al., 2009, 2008), decreases in $f_{\mathrm{H}}$ variability in response to tachycardia were accompanied by shifts in the amplitude of dominant frequencies in the power spectrum. There was little effect of autonomic tonus on $f_{\mathrm{V}}$ at $0^{\circ} \mathrm{C}$ (both cholinergic and adrenergic $<5 \%$; Table 1), as found previously using bilateral vagotomy. Although a modest $(14 \%)$ cholinergic tone was established at $5^{\circ} \mathrm{C}$, no rise in adrenergic tone was observed $(2 \%)$, thereby maintaining a similar sympathovagal balance (cholinergic:adrenergic tonus of 7.5 acutely, 7.0 on acclimation).

Importantly, on chronic exposure to $5^{\circ} \mathrm{C}$, there was only a small $(7 \%)$ decrease in $f_{\mathrm{H}}$ and a modest $(20 \%)$ fall in $f_{\mathrm{V}}$, with apparent $Q_{10}$ remaining high (2.69 and 3.15, respectively), such that $f_{\mathrm{V}} / f_{\mathrm{H}}(1.81)$ reduced the increase seen on acute warming but failed to return to control levels. This contrasts with earlier work that suggests thermal acclimation decreased cardiovascular strain (Robinson et al., 2011); whether this reflects the slightly lower temperature used $\left(4^{\circ} \mathrm{C}\right)$, an allometric influence $\left(P\right.$. borchgrevinki $\sim 100 \mathrm{~g}$ ) or low $f_{\mathrm{H}}$ variability in this species is unclear. Both cholinergic (34\%) and adrenergic

\section{Table 1. Effect of autonomic blockade on the cardiorespiratory response to acute and chronic elevated temperature in Notothenia coriiceps}

\begin{tabular}{|c|c|c|c|}
\hline & \multirow[b]{2}{*}{$0^{\circ} \mathrm{C}$} & \multicolumn{2}{|c|}{$5^{\circ} \mathrm{C}$} \\
\hline & & Acute & Chronic \\
\hline \multicolumn{4}{|l|}{ Atropine } \\
\hline$f_{\mathrm{H}}\left(\right.$ beats $\min ^{-1}$ ) & $23.9 \pm 0.8$ & $30.1 \pm 2.1^{* *}$ & $29.5 \pm 1.9^{* *}$ \\
\hline SDRR (ms) & $94 \pm 12$ & $74 \pm 31$ & $77 \pm 23$ \\
\hline SDSD (ms) & $24 \pm 27$ & $16 \pm 16$ & $54 \pm 23$ \\
\hline$f_{\mathrm{V}}\left(\right.$ breaths $\min ^{-1}$ ) & $21.2 \pm 0.2$ & $53.0 \pm 5.5^{* * *}$ & $45.0 \pm 4.3^{* * *}$ \\
\hline \multicolumn{4}{|l|}{ Atropine+propranolol } \\
\hline$f_{\mathrm{H}}\left(\right.$ beats $\left.\min ^{-1}\right)$ & $21.2 \pm 0.2$ & $25.0 \pm 2.3$ & $25.0 \pm 1.8$ \\
\hline SDRR (ms) & $24 \pm 16$ & $31 \pm 21$ & $47 \pm 12$ \\
\hline SDSD (ms) & $45 \pm 21$ & $41 \pm 18$ & $64 \pm 23$ \\
\hline$f_{\mathrm{V}}\left(\right.$ breaths $\min ^{-1}$ ) & $22.1 \pm 1.7$ & $54.0 \pm 1.8^{* * *}$ & $44.0 \pm 2.1^{* * *, \text { 斗 }}$ \\
\hline
\end{tabular}

Atropine, muscarinic receptor blockade; atropine+propranolol, complete autonomic receptor blockade. Acute refers to readings taken following a temperature rise over 1 day; chronic refers to readings taken after 6 weeks acclimation. SDRR, standard deviation of the R-R interval; SDSD, standard deviation of the successive differences of $R-R$ intervals.

Data are means \pm s.e.m., $N=8$ animals in each group. ${ }^{* *} P<0.01,{ }^{* * *} P<0.001$ versus $0^{\circ} \mathrm{C} ;{ }^{\ddagger \ddagger} P<0.01$ versus acute (factorial ANOVA). tonus $(18 \%)$ were similar to that seen with acute warming, as reflected in the small recovery of long-term $f_{\mathrm{H}}$ variability on chronic exposure (SDRR $=122 \pm 23 \mathrm{~ms}$, n.s.). Similarly, the cardiovascular responses of $4^{\circ} \mathrm{C}$-acclimated $P$. borchgrevinki are under dominant cholinergic control, and concomitant changes in ventilation maintain CRC (Robinson et al., 2011). Interestingly, a broadly similar temperature correlation with $f_{\mathrm{H}}$ variability was observed when comparing Antarctic notothenioids with temperate zone relatives; the same SDRR:SDSD ratio $(0.74)$ was seen in rested P. angustata (Campbell and Egginton, 2007). Handling stress increased this to a similar extent (1.14) to acute warming (1.20). However, short-term variability in cardiac rhythmicity showed partial recovery on acclimation $(\mathrm{SDSD}=251 \pm 67 \mathrm{~ms}, P=0.06)$, thereby reducing SDRR:SDSD (0.49), implying that the duration of exposure was sufficient to observe the start of a true acclimation process.

Consistent with these findings, there was no change in $\dot{M}_{\mathrm{O}_{2}}$ on acclimation and hence the oxygen pulse was $>20 \%$ higher at $5^{\circ} \mathrm{C}$ than at $0^{\circ} \mathrm{C}$. This cannot simply be a prolonged stress response as high cholinergic tonus was evident, but may include the energetic cost of phenotypic remodelling to cope with the physiological challenge, e.g. increased gene expression/protein turnover associated with higher osmoregulatory and/or ionoregulatory activity. Interestingly, the values for $\dot{M}_{\mathrm{O}_{2}}$ at high temperature are lower than those following feeding at $0^{\circ} \mathrm{C}$ (Campbell et al., 2008), but the high apparent $Q_{10}$ (4.31) indicates persistent physiological strain. Visual observations also revealed a higher activity pattern, contributing to the elevated $\dot{M}_{\mathrm{O}_{2}}$, and a greater frequency of rapid head shakes reminiscent of vestibular dysfunction. Hyperactivity, uncoordinated movements and occasional spasms before the loss of a righting response have also been observed with other populations of $N$. coriiceps subjected to thermal acclimation (K. O'Brien and E. L. Crockett, unpublished observations), again implicating disturbances to the nervous system in the behavioural traits observed. Indeed, neural sensitivity to warming may play a role in an organism's thermotolerance associated with brain membrane compositional changes, thought to be most evident in Antarctic fishes (Somero and DeVries, 1967).

Antarctic marine organisms may have a limited ability to respond to environmental temperature change, but $P$. borchgrevinki was able to accommodate a $5^{\circ} \mathrm{C}$ rise by adjusting resting metabolic rate and ventilation frequency, although $\dot{M}_{\mathrm{O}_{2}}$ during recovery from exhaustive exercise was similar between ambient- and warmacclimated fish (Robinson and Davison, 2008). Our observations appear to conflict with recent findings that nototheniids increase their thermotolerance when acclimated to $4^{\circ} \mathrm{C}$ for $1-3$ weeks (Bilyk and DeVries, 2011), and either maintain or show greater factorial scope for cardiac output when acclimated to $4^{\circ} \mathrm{C}$ for $4-5$ weeks (Bilyk and DeVries, 2011; Franklin et al., 2007). It is possible that there may be some difference in sensitivity to heat between fishes from the Peninsula and McMurdo Sound, e.g. a similar factorial increase in $f_{\mathrm{H}}, f_{\mathrm{V}}$ and $\dot{M}_{\mathrm{O}_{2}}$ as seen in $N$. coriiceps was observed in $P$. borchgrevinki, but in the latter case showed either partial or full recovery after acclimation (Robinson and Davison, 2008; Robinson et al., 2011). The current study suggests that caution is needed in interpreting such findings to be evidence for true thermal compensation. In addition, the time scale of imposed changes and the consequent trade-off among, for example, cardiovascular responses and growth/reproduction may alter opinion as more data are gathered (Beers and Jayasundara, 2015). For example, Trematomus bernacchii acclimated to $4{ }^{\circ} \mathrm{C}$ reduced growth by $84 \%$ and suffered a mortality rate of $33 \%$ (Sandersfeld et al., 2015). We therefore conclude that although nototheniids may not be as 
restricted to their current stenothermal niche as previously thought, assumptions regarding their ability to fully acclimatise to warmer waters require longer term studies than those managed so far. Until such data become available, the mechanisms underlying responses to anticipated environmental changes are unclear, and predictions regarding adaptive capacity remain speculative.

\section{Acknowledgements}

The help of Kieron Fraser and Lloyd Peck of the British Antarctic Survey, and the summer staff of the Rothera Research Station, is gratefully acknowledged.

\section{Competing interests}

The authors declare no competing or financial interests.

\section{Author contributions}

S.E. designed the experiments, analysed the data, interpreted the results and drafted the manuscript; H.A.C. executed the experiments, analysed the data and revised the manuscript.

\section{Funding}

This research was funded by the Natural Environment Research Council (GR3/ AFI12/43).

\section{References}

Beers, J. M. and Jayasundara, N. (2015). Antarctic notothenioid fish: what are the future consequences of 'losses' and 'gains' acquired during long-term evolution at cold and stable temperatures? J. Exp. Biol. 218, 1834-1845.

Bilyk, K. T. and DeVries, A. L. (2011). Heat tolerance and its plasticity in Antarctic fishes. Comp. Biochem. Physiol. A Mol. Integr. Physiol. 158, 382-390.

Campbell, H. A. and Egginton, S. (2007). The vagus nerve mediates cardiorespiratory coupling that changes with metabolic demand in a temperate nototheniod fish. J. Exp. Biol. 210, 2472-2480.
Campbell, H. A., Klepacki, J. Z. and Egginton, S. (2006). A new method in applying power spectral statistics to examine cardio-respiratory interactions in fish. J. Theor. Biol. 241, 410-419.

Campbell, H. A., Fraser, K. P. P., Bishop, C. M., Peck, L. S. and Egginton, S. (2008). Hibernation in an Antarctic fish: on ice for winter. PLOS ONE 3, e1743.

Campbell, H., Davison, W., Fraser, K. P. P., Peck, L. S. and Egginton, S. (2009) Heart rate and ventilation in Antarctic fishes are largely determined by ecotype. J. Fish Biol. 74, 535-552.

Egginton, S., Campbell, H. and Davison, W. (2006). Cardiovascular control in Antarctic fish. Deep Sea Res. // Top. Stud. Oceanogr. 53, 1115-1130.

Farrell, A. P., Eliason, E. J., Sandblom, E. and Clark, T. D. (2009). Fish cardiorespiratory physiology in an era of climate change. Can. J. Zool. 87, 835-851.

Franklin, C. E., Davison, W. and Seebacher, F. (2007). Antarctic fish can compensate for rising temperatures: thermal acclimation of cardiac performance in Pagothenia borchgrevinki. J. Exp. Biol. 210, 3068-3074.

O'Brien, K. M. and Crockett, E. L. (2013). The promise and perils of Antarctic fishes. EMBO Rep. 14, 17-24.

Robinson, E. and Davison, W. (2008). The Antarctic notothenioid fish Pagothenia borchgrevinki is thermally flexible: acclimation changes oxygen consumption. Polar Biol. 31, 317-326.

Robinson, E., Egginton, S. and Davison, W. (2011). Warm-induced bradycardia and cold-induced tachycardia: mechanisms of cardiac and ventilatory control in a warm-acclimated Antarctic fish. Polar Biol. 34, 371-379.

Sandersfeld, T., Davison, W., Lamare, M. D., Knust, R. and Richter, C. (2015). Elevated temperature causes metabolic trade-offs at the whole-organism level in the Antarctic fish Trematomus bernacchii. J. Exp. Biol. 218, 2373-2381.

Seebacher, F., Davison, W., Lowe, C. J. and Franklin, C. E. (2005). A falsification of the thermal specialization paradigm: compensation for elevated temperatures in Antarctic fishes. Biol. Lett. 1, 151-154.

Somero, G. N. and DeVries, A. L. (1967). Temperature tolerance of some Antarctic fishes. Science 156, 257-258. 